\title{
Fracture toughness of CTBN modified PF particleboard based on equal deflection rigidity
}

\author{
Haiyang Zhang ${ }^{1, *}$, Qin $\mathrm{Qu}^{1}$, and Yang $\mathrm{He}^{1}$ \\ ${ }^{1}$ Materials Science and Engineering, Nanjing Forestry University, 210037 Longpan Road,Nanjing, China
}

\begin{abstract}
The fracture toughness of particleboard should be evaluated when it was intended to use in the structure system. Single edge notched beam (SENB) test method was employed to measure stress intensity factor (SIF) of the internal middle layer of the PF and CTBN modified PF particleboard. Equal deflection rigidity algorithm (EDRA) was used to homogenized the sandwich bi-material beam in order to make the test procedure match ASTM E399-2017. The results shown that the optimized CTBN addition was among $8 \%$ to $12 \%$ and the improve ratio of SIF of the particleboard middle layer was $27.27 \%$. Owing to the different broken mechanism, the tested fracture performance show more stability compared to the traditional internal bonding (IB) test. But the fracture test strongly depend on the notched incision morphology.
\end{abstract}

\section{INTRODUCTION}

Owing to good processing property, superior bonding performance, better water resistance, high endurance quality and moderate price, the application of phenol resin (PF) in wood based composites is very common ${ }^{[1-3]}$. And PF bonded wood based panels are mainly used in the structure environment. As we know, the toughness of the materials must be considered in the application of structural engineering which affect the security of the final products. However, the cured PF resin is very brittle making the wood based composites lack of toughness. A lot of research work has been done to make the thermo-corsslinked PF resin more ductility. Bismaleimide, cashew shell oil, linseed oil and so on have been applied to modify PF resin, but the targeted modification effect is not very nice $e^{[4-8]}$. Carboxylterminated butadieneacrylonitrile copolymer (CTBN) has been used to improve the performance of PF resin especially in the production of particleboard in this paper.

The bonding performance of particleboard is usually measured by plane tensile strength. In order to better characterize properties of composites, fracture toughness has been recommended in this paper to quantitatively describe mechanical performance in different direction of the particleboard. The determination of fracture toughness based on linear elastic fracture mechanics approach (ASTM E399-2017) has been modified because of the thickness of the composite is very limited. So the aims of the paper is to explore the feasibility of the fracture toughness test in the particleboard properties evaluation and how the CTBN addition can influence the final toughness of the particleboard. This interesting research introduces new directions and methods to consider the wood based materials and provide base data for broaden the application of particleboard.

\subsection{Materials and methods}

\subsubsection{Materials and particleboards preparing}

All the particleboards manufactured in the expriment were based on the poplar (Populus sp.) particles with about $0.1-0.3 \mathrm{~mm}$ thickness and $3-10 \mathrm{~mm}$ long. The particles were first screened after be produced and dried to $3-4 \%$ moisture content. PF with a solid content of $45.15 \%$ was sprayed onto the surfaces of the particles while the particles were rolling over. The viscosity of $\mathrm{PF}$ was $255 \mathrm{mPa} \cdot \mathrm{m}$ and $\mathrm{pH}$ was $10.1\left(25^{\circ} \mathrm{C}\right)$.

Carboxyl-terminated poly ( butadiene-coacrylonitrile) (CTBN) was purchased from Jingjiang Tonggao chemical co.LTD. The effect of CTBN content on the performance of the final particleboards were studied with single factor experimental design. $4 \%, 8 \%$, $12 \%$ and $16 \%$ weight percentage CTBN of the solid PF was firstly mixed with the resin except the control group and then be sprayed. the designed density of the particleboard was $0.65 \mathrm{~g} / \mathrm{cm}^{3}$ and the measured density of the final board was among $0.63-0.67 \mathrm{~g} / \mathrm{cm}^{3}$. Considering the relatively small density differences, the influence of the density on the fracture toughness was neglected in this experiment. The solid resin (PF and CTBN) content based on the dry particle weight was $8 \%$. the hot pressure process parameters were $180{ }^{\circ} \mathrm{C}, 40$ $\mathrm{s} / \mathrm{mm}$ and the thickness of the particleboards were controlled with a gauge. 


\subsubsection{Fracture toughness test}

The mode-I fracture toughness with the crack opening along the middle layer which is the minimum density part of the particleboard was tested by a sandwich three point bend. The inter middle layer was also the traditional internal bonding test part. Two pine bars were bonded to the surfaces of the particleboard with two component epoxy and the dimensional sets were listed in table 1.

Table 1. The dimension parameters of the SENB samples.

\begin{tabular}{|c|c|c|}
\hline Parameters & Descriptions & Value \\
\hline $\mathrm{w}$ & Width & $60 \mathrm{~mm}$ \\
\hline $\mathrm{h}$ & Thickness & $20 \mathrm{~mm}$ \\
\hline $\mathrm{L}_{0}$ & Total Length & $300 \mathrm{~mm}$ \\
\hline $\mathrm{L}$ & Test Span & $240 \mathrm{~mm}$ \\
\hline $\mathrm{l}_{\mathrm{b}}$ & $\begin{array}{c}\text { Lateral bar } \\
\text { length }\end{array}$ & $145 \mathrm{~mm}$ \\
\hline $\mathrm{t}$ & $\begin{array}{c}\text { Particleboard } \\
\text { thickness }\end{array}$ & $10 \mathrm{~mm}$ \\
\hline $\mathrm{a}$ & $\begin{array}{c}\text { Pre-crack } \\
\text { length }\end{array}$ & $30 \pm 2 \mathrm{~mm}$ \\
\hline $\mathrm{a} / \mathrm{w}$ & $\begin{array}{c}\text { Relative crack } \\
\text { length }\end{array}$ & $50 \pm 4 \%$ \\
\hline
\end{tabular}

A micro-band saw was used to machine the first 28 $\mathrm{mm}$ depth notch with $0.65 \mathrm{~mm}$ thickness band saw blade. The top-most $2 \mathrm{~mm}$ was made by a sharp razor to ensure the crack would be sharp enough so that an even sharper crack will not result in significantly lower values of the measured properties. So the total length of the pre-crack is $30 \mathrm{~mm}$ which is $50 \%$ of the specimen width. All the fracture toughness test procedure was operated according to ASTM E399-2017 with the single-edge-notch bending (show in fig.1). The determine of $\mathrm{F}_{\mathrm{Q}}$ is shown in fig.2.

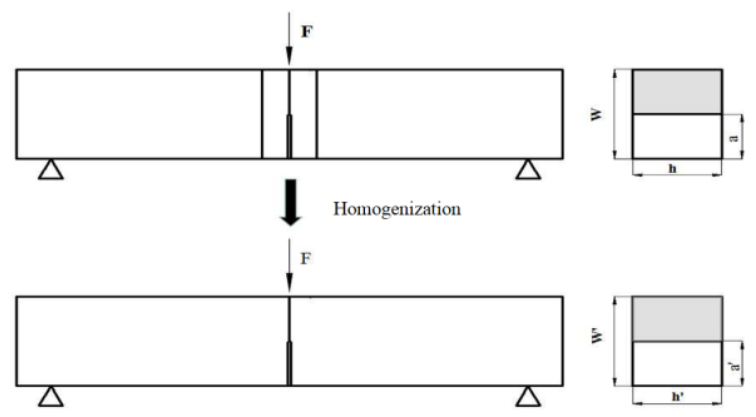

Fig. 1. The SENB test specimens under three point bending and the homogenization diagram.

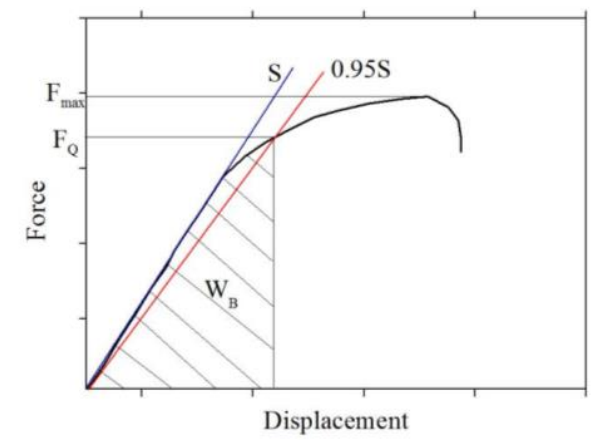

Fig. 1. The determine of $\mathrm{F}_{\mathrm{Q}}$ by $95 \%$ stiffness reduction.

The bimaterial three point bending beam was conversed into a single uniform pine wood beam by equal deflection rigidity methods as described by Qizhi Wang $^{[9]}$. So the stress intensity factor (SIF) calculation formula of ASTM E399 stanard is as follows:

$$
\begin{gathered}
K_{I C m}=\frac{F_{Q} S}{h w^{3 / 2}} \cdot f\left(\frac{a}{w}\right)=\frac{F_{Q} S}{h w^{3 / 2}} \cdot K_{m} \\
K_{m}=f\left(\frac{a}{w}\right)=3\left(\frac{a}{w}\right)^{1 / 2} \frac{1.99-\left(\frac{a}{w}\right)\left(1-\frac{a}{w}\right)\left[2.15-3.93 \frac{a}{w}+2.7\left(\frac{a}{w}\right)^{2}\right]}{2\left(1+2 \frac{a}{w}\right)\left(1-\frac{a}{w}\right)^{3 / 2}}
\end{gathered}
$$

The upper limit SIF was tested and calculated with only the height of the cross section was changed during beam homogenisation ${ }^{[10-17]}$. The calculation formula is as follows and the $\mathrm{E}_{\mathrm{p} 3} / \mathrm{E}_{\mathrm{w} 1}$ is $0.068 . \mathrm{E}_{\mathrm{p} 3}$ is $416 \mathrm{MPa}$ and $\mathrm{E}_{\mathrm{w} 1}$ is $6130 \mathrm{MPa}$ measured by acoustic method. $\mathrm{E}_{\mathrm{p} 3}$ is the elastic constant along the thickness of the particleboard. $\mathrm{E}_{\mathrm{w} 1}$ is the elastic constant in the wood fiber direction. the two directions are in the length direction of the test beam.

$$
\begin{gathered}
K_{I C u}=\frac{F_{Q} S}{h w^{3 / 2}} \cdot\left(\frac{E_{p 3}}{E_{w 1}}\right)^{1 / 2} \cdot f\left(\alpha_{u}\right)=\frac{F_{Q} S}{h w^{3 / 2}} \cdot K_{u} \\
K_{u}=\left(\frac{E_{p 3}}{E_{w 1}}\right)^{1 / 2} \cdot f\left(\alpha_{u}\right) \\
\alpha_{u}=\frac{a^{\prime}}{w^{\prime}}=\frac{a}{w}\left(\frac{E_{p 3}}{E_{w 1}}\right)^{1 / 3}+1-\left(\frac{E_{p 3}}{E_{w 1}}\right)^{1 / 3}
\end{gathered}
$$

The lower limit SIF was tested and calculated with both the height and thickness of the cross section were changed in the same proportion. The calculation formula is as follows:

$$
\begin{gathered}
K_{I C l}=\frac{F_{Q} S}{h w^{3 / 2}} \cdot\left(\frac{E_{p 3}}{E_{w 1}}\right)^{5 / 8} \cdot f\left(\frac{a^{\prime}}{w^{\prime}}\right)=\frac{F_{Q} S}{h w^{3 / 2}} \cdot K_{l} \\
K_{l}=\left(\frac{E_{p 3}}{E_{w 1}}\right)^{5 / 8} \cdot f\left(\alpha_{l}\right)
\end{gathered}
$$




$$
\alpha_{l}=\frac{a^{\prime}}{w^{\prime}}=\frac{a}{w}\left(\frac{E_{p 3}}{E_{w 1}}\right)^{1 / 4}+1-\left(\frac{E_{p 3}}{E_{w 1}}\right)^{1 / 4}
$$

\section{Results and discussion}

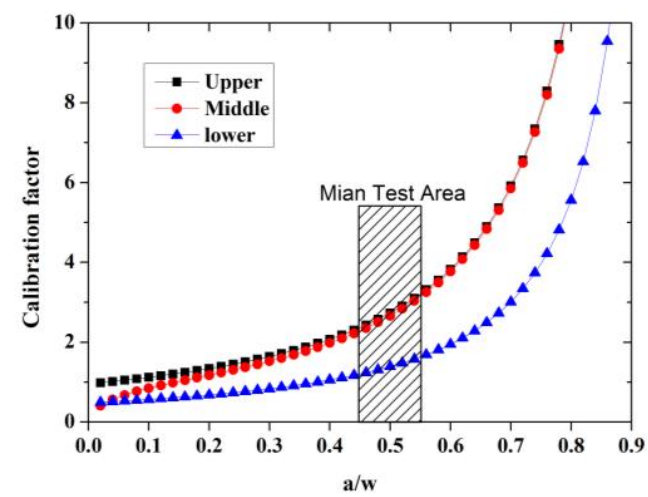

Fig. 2. The comparsion of $\mathrm{K}_{\mathrm{m}}, \mathrm{K}_{\mathrm{u}}$ and $\mathrm{K}_{\mathrm{l}}$.

A comparison of the calibration factors based on above three methods is show in fig.2. As we can see, the $K_{u}$ is very close to $K_{m}$ when $\mathrm{a} / \mathrm{w}$ is more than 0.3 and that totally include the range of the test scope. The difference between $\mathrm{K}_{1}$ and the other two is higher and that will influence the final test fracture toughness.

The middle, upper and lower SIFs measured by SENB method modified by beam homogenisation are shown in table 1. As we can see, the calculated middle and upper SIFs are very close to each other and their average difference ratio are less than $3.29 \%$ compared to the middle value. The significant difference between them was checked by T test by SPSS 16.0 software and the results show that there were no statistical significance difference no matter whether CTBN added amount was changed. this is because the elastic constants of the particleboard along the thickness is only $6.79 \%$ of the pine in the wood fiber direction and the elastic constants difference have a distinct influence on the final middle, upper and lower tested SIFs. But the measured lower SIFs only about $50 \%$ of the other two vaules also owing to the big elastic constants to produce the SENB test beam.

\begin{tabular}{|c|c|c|c|c|}
\hline \multirow{2}{*}{ CTBN } & \multirow{2}{*}{ Statistics } & \multicolumn{3}{|c|}{$\mathrm{K}_{\mathrm{IC}}\left(\mathrm{kPa} \mathrm{m}^{0.5}\right)$} \\
\cline { 3 - 5 } & & Middle & Upper & Lower \\
\hline \multirow{2}{*}{0} & Mean & 55 & 56 & 29 \\
\cline { 2 - 5 } & SD & 7.5 & 5.6 & 3.6 \\
\hline \multirow{2}{*}{4} & Mean & 61 & 63 & 32 \\
\cline { 2 - 5 } & SD & 7.5 & 6.3 & 4.2 \\
\hline \multirow{2}{*}{8} & Mean & 66 & 68 & 34 \\
\cline { 2 - 5 } & SD & 6.5 & 7.1 & 3.9 \\
\hline \multirow{2}{*}{12} & Mean & 70 & 72 & 37 \\
\cline { 2 - 5 } & SD & 8.2 & 8.1 & 4.3 \\
\hline \multirow{2}{*}{16} & Mean & 70 & 72 & 37 \\
\cline { 2 - 5 } & SD & 8.9 & 8.2 & 3.8 \\
\hline
\end{tabular}

Table 3. Font styles for a reference to a journal article.

The loading mount of CTBN in the PF bonded particleboard system really has significant influence on the final fracture toughness of particleboard interlayer. The faracture toughness of particleboard firstly increased as the CTBN added below $12 \%$. When surpass $12 \%$, the performance almost had no change. So the optimised CTBN mix amount was among $8 \%$ to $12 \%$ in the PF bonded poplar ordinary particleboard and it is a effective method to improve the toughness of wood based composites when PF resin is used. The promotion rate of the fracture toughness of the PF bonded particleboard in this experiment reached $27.27 \%$.

The internal bonding strength of the particleboard was also measured and the results show that CTBN addtion can not imporve the final IB strength. This is because the traditional IB test depend on the defects in the whole particlebaord. While, the SENB test was contingent on the precrack state and the stress conditions at the surroudning areas. And analyzed from the coefficient of variation, the SENB test value was about $11 \%$ which was less than $26 \%$ of the IB test.

The acknowledgements should be typed in 9-point Times, without title.

\section{References}

1. A. Knop, W. Scheib, Chemistry and application of phenolic resins (Springer, 1979)

2. N. Cetin, N. ÖZMEN, Use of organosolv lignin in phenol - formaldehyde resins for particleboard production: I. Organosolv lignin modified resins, Int. J. Adhes. Adhes, 22, 6: 477-480 (2002)

3. L. Pilato, Phenolic resins: a century of progress, (Springer, 2010)

4. A. Gu, G. Liang, L. Lan, Modification of polyaralkyl - phenolic resin and its copolymer with bismaleimide, J. Appl. Polym. Sci., 59, 6, 975-979 (1996)

5. P. Saha, S. Manna, R. Sen, D. Roy, B. Adhikari, . Durability of lignocellulosic fibers treated with vegetable oil - phenolic resin. Carbohydrate Polymers, 87, 2, 1628-1636 (2012)

6. G. Cayl, H. Kusefoglu, Polymerization of linseed oil with phenolic resins. J. Appl. Polym. Sci., 118, 2, 849-856 (2010)

7. V. Turkington, R. Moore, W. Butler, R. Shuey, Phenolic Resin Varnishes Influence of Linseed Oil 
on Film Properties. Ind. Eng. Chem., 27, 11, 1321$1325(1935)$

8. C. Kaynak, A. Ozturk, T. Tincer,. Flexibility improvement of epoxy resin by liquid rubber modification. Polym. Int., 51, 9, 749-756 (2002)

9. Q. Wang, A sandwich three-point bend specimen for testing mode-I interlaminar fracture toughness for fiber-reinforced composite materials. Int. J. Fracture, 85, 3, 231-240 (1997)

10. H. Zhang, A. Pizzi, X. Lu, Z. Wang, Study of the end-grain butt joints obtained by friction welding of moso bamboo, BioResources, 12, 3, 6446-6457 (2017)

11. H. Zhang, Q. He, X. Lu, A. Pizzi, C. Mei, X. Zhan, Energy Release Rate Measurement of Welded Bamboo Joints, J. Renew. Mater., 6, 5,450-456 (2018).

12. H. Zhang, A. Pizzi,X. Lu,G. Janin, Palmyra palm bonding by vibrational welding. Eur. J Wood Wood Prod., 72, 5, 693-695(2014)

13. H. Zhang, H. Luo, X. Lu, Reliability of compression strength of hennon bamboo-reinforced extruded tubular particleboard, BioResources, 9, 2, 2696-2704 (2014)

14. H. Zhang, X. Lu, Modeling of the elastic properties of laminated strand lumber, Wood Res-Slovakia, 59, $1,1-10(2014)$

15. H. Zhang, J. Liu, $X$. Lu, Reducing the formaldehyde emission of composite wood products by cold plasma treatment. Wood ResSlovakia, 58, 4, 607-616 (2013)

16. H. Zhang, A. Pizzi, X. Lu, X. Zhou, Optimization of tensile shear strength of linear mechanically welded outer-to-inner flattened moso bamboo (Phyllostachys pubescens). BioResources, 9, 2, 2500-2508 (2014)

17. H. Zhang, A. Pizzi, X. Zhou, X. Lu, Z. Wang, The study of linear vibrational welding of moso bamboo. J. Adhes. Sci. and Techno., 32, 1, 1-10 (2018) 